\title{
Tuberculosis elimination in Canada: Truce or victory?
}

\author{
Richard Long MD, Edward Ellis MD MPH
}

See also page E473 and www.cmaj.ca/lookup/doi/10.1503/cmaj.150011

$\mathrm{A}$ ccording to the World Health Organization (WHO), Canada is a low-incidence country when it comes to tuberculosis (TB), with fewer than 10 cases per 100000 population annually. As such, elimination of TB $(<1$ case per 1000000 annually) by the year 2050 should be achievable. ${ }^{1}$ Unfortunately, our poor achievement with respect to meeting pre-elimination targets in Canada puts this goal into question. In 1997, the National Consensus Conference on Tuberculosis called for a $5 \%$ annual reduction in the number of new cases, ${ }^{2}$ and in 2006, the WHO Global Plan to Stop TB 2006-2015 urged Canada to reach a target incidence of 3.6 per 100000 annually by $2015^{3}$ a target that was announced by the federal minister of health in 2006 and reiterated in $2013 .{ }^{4}$ But neither the 1997 nor the 2006 target has been or is likely to be reached (Figure 1). One might ask whether George Jasper Wherrett was prophetic in 1977 when he wrote:

The public has lost its fear of tuberculosis and [has] become complacent. ... There is the fear that this complacency will lead to toleration of the disease and that it will remain for many years to come a source of infection, with its ups and downs, and at best there will be only a truce with the disease rather than a victory over it. ${ }^{5}$

In Canada, TB is concentrated in two minority groups: foreign-born people and indigenous people. The incidence in each group is 16 or more times higher than in the Canadian-born non-indigenous population. Major clinical obstacles to successful TB control, including drug resistance and HIV coinfection, are also more common in these minority groups, with drug resistance being more common among foreign-born people and HIV co-infection being more common among foreign-born people from sub-Saharan Africa and Canadian-born indigenous people. ${ }^{6,7}$ Tuberculosis is now rare in the Canadian-born non-indigenous group, occurring mainly in older people and inner-city poor and homeless people. Moving closer to elimination in the Canadian-born non-indigenous population may inadvertently, or through indifference, impede successful control in the minority groups.

Unfortunately, any progress toward TB elimination is frustrated by the fact that Canada's elimination plan, assuming the recommendations of the 1997 consensus conference constituted such a plan, has largely been forgotten. ${ }^{2}$ The national committee the conference recommended for providing advice and monitoring the plan has since been discontinued, and before this happened, a national consensus on a set of performance indicators allowing all stakeholders to measure progress and address problem areas had not been achieved. Resurrection of the plan, integrated with extant guidance and framework documents, would better allow us to reach national objectives for TB control, finalize performance targets and indicators, and create a means to monitor progress toward those objectives annually. ${ }^{8,9}$

Both the United States and Western Europe have developed explicit plans for the elimination of TB. ${ }^{10,11}$ The US Centers for Disease Control and Prevention funds the Advisory Council for the Elimination of Tuberculosis. In Europe, reestablishment and maintenance of a national tuberculosis network in terms of funding, human resources and facilities is considered vital. ${ }^{11}$ Acting on a basic element of the WHO Stop TB initiative to monitor and evaluate performance and impact, the US developed a secure Web-based monitoring system that uses routinely collected surveillance data on individual TB cases to measure the performance of TB control programs at local and state levels. With it, they can prioritize improvement efforts, focus on key disease control activities and track progress toward national program objectives. ${ }^{12}$ For a small cost, equivalent to that of managing one or two cases of TB, Canada could and should set up a national advisory committee, re-establish a plan and monitor as well as guide its implementation.

\section{- Ker pOINTS}

- Canada's poor achievement with respect to meeting pre-elimination targets puts achieving TB elimination by 2050 into question.

- Foreign-born people from high-incidence countries and indigenous people are the most likely to acquire TB.

- Government, nongovernmental organizations, academia, communities and patients need to work together with a national advisory committee to develop a plan and a monitoring framework to eliminate TB.

- Concerned health care professionals can help by urging their provincial/territorial government officials to support the establishment of a national TB advisory committee. 
With respect to foreign-born people, the numbers arriving each year from high-incidence countries are large compared with those from other lowincidence countries such as the US. Many have latent TB infection acquired in their country of birth, later reactivating in Canada. Currently, only new immigrants with a history of TB or evidence of healed TB on a chest radiograph are referred by Citizenship and Immigration Canada for medical surveillance. The primary objective of this referral process is to identify those who have active TB at the time of immigration. However, it is widely regarded as inadequate if TB elimination targets are to be met. In addition to improved efficiencies in the current process, revision might include referral or notification of people recently arrived from highincidence countries and those with risk factors for reactivation of latent TB other than signs of healed TB on a chest radiograph. ${ }^{6}$ Provincial and territorial TB programs are in a position to assist with revision of Citizenship and Immigration Canada's referral process - present and future, overseas and in Canada - but there must be a forum to do so.

With respect to indigenous people, equitable access to high-quality diagnosis and care is needed, particularly in communities in the middle and far north, where TB tends to occur as focal outbreaks or has a sustained high incidence. But as important, if not more important than these proximate considerations, is the need to address the upstream determinants of indigenous health. These include not only classic socioeconomic and connectivity deficits, the most striking of which from a TB perspective is the ongoing crisis in housing, but also indigenous-specific determinants related to colonization, globalization, migration, loss of language and culture, and disconnection from the land. ${ }^{13,14}$ Critical to addressing these upstream determinants is the need to see indigenous people as full partners in contemporary life and recognize their right to selfdetermination regardless of formal nationhood.

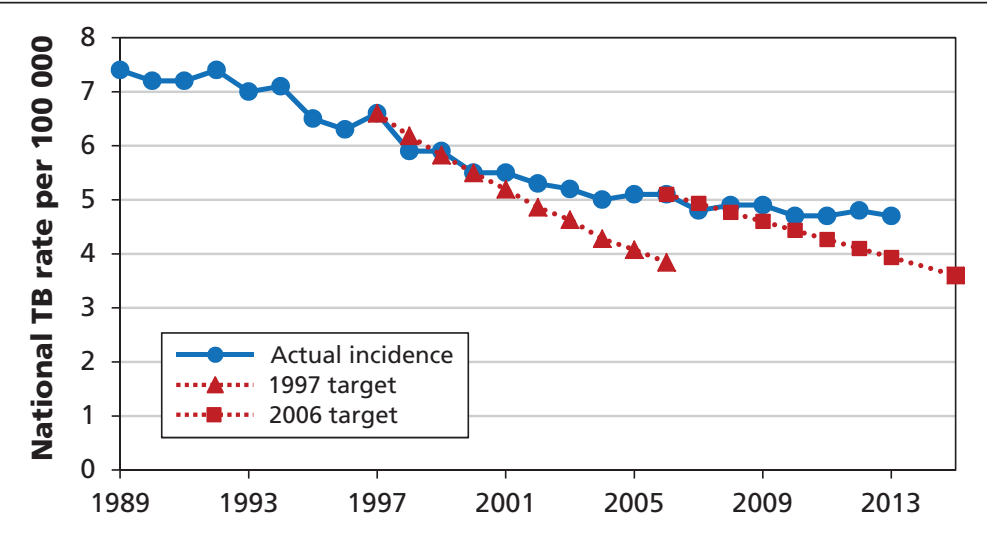

Figure 1: Actual incidence of tuberculosis in Canada 1989-2013, and projected rates based on pre-elimination targets set in $1997^{2}$ and $2006 .^{3}$ [Source for actual rates: Canadian Tuberculosis Reporting System, Public Health Agency of Canada].
For Canada, a country with universal health care insurance and the eleventh highest gross domestic product in the world, victory over TB — not just a truce — should be our goal. Canada has an obligation to its citizens and its international partners. Its government has committed to specific preelimination and elimination targets. With the establishment of a national advisory committee, a plan, a monitoring framework and targeted interventions aimed at the high-risk groups, all levels of government, nongovernmental organizations, academia, communities and patients can eliminate TB, but we must work together. Concerned health care professionals can help by urging their provincial/ territorial government officials to support the establishment of a national TB advisory committee.

\section{References}

1. Lönnroth K, Migliori GB, Abubakar I, et al. Towards tuberculosis elimination: an action framework for low-incidence countries. Eur Respir J 2015;45: 928-52.

2. Proceedings of the National Consensus Conference on Tuberculosis, December 3-5, 1997. Can Commun Dis Rep 1998;24(S2).

3. Global Plan to Stop TB 2006-2015. Geneva: World Health Organization; 2006. Available: WHO/HTM/STB/2006.35 (accessed 2015 July 16).

4. Aglukkaq L. Ministerial message - World Tuberculosis Day. 2010 Mar. 24. Available: www.leonaaglukkaq.ca/media/riding -news/ministerial-message---world-tuberculosis-day (accessed 2015 July 16)

5. Wherrett GJ. The miracle of the empty beds. A history of tuberculosis in Canada. Toronto: University of Toronto Press; 1977.

6. The Canadian tuberculosis standards, 7th edition. Ottawa: Public Health Agency of Canada and Canadian Thoracic Society; 2014. Available: www.respiratoryguidelines.ca/sites/all/files/Canadian_ TB_Standards_7th_Edition_ENG.pdf (accessed 2015 July 16).

7. Long R, Niruban J, Heffernan C, et al. A 10-year population-based study of 'op-out' HIV testing of tuberculosis patients in Alberta, Canada: National Implications. PLoS ONE 2014;9:e98993.

8. Guidance for tuberculosis prevention and control programs in Canada. Ottawa: Pan-Canadian Public Health Network; 2012.

9. Tuberculosis prevention and control in Canada. A federal framework for action. Ottawa: Public Health Agency of Canada; 2014. Available: www.phac-aspc.gc.ca/tbpc-latb/pubs/tpc-pct/ index-eng.php (accessed 2015 July 16).

10. Dowdle WR, Centers for Disease Control and Prevention. A strategic plan for the elimination of tuberculosis in the United States. MMWR Morb Mortal Wkly Rep 1989;38(Suppl 3):1-25.

11. Broekmans JF, Migliori GB, Rieder HL, et al. European framework for tuberculosis control and elimination in countries with a low incidence. Eur Respir J 2002;19:765-75.

12. Centers for Disease Control and Prevention. Monitoring tuberculosis programs - National Tuberculosis Indicator Project, United States, 2002-2008. MMWR Morb Mortal Wkly Rep 2010;59:295-8.

13. King M, Smith A, Gracey M. Indigenous health part 2: the underlying causes of the health gap. Lancet 2009;374:76-85.

14. Report of the Special Rapporteur on the rights of indigenous peoples, James Anaya on the situation of indigenous peoples in Canada [no. A/HRC/27/52/Add.2]. New York: Twenty-seventh session of the Human Rights Council, United Nations General Assembly; 2014. Available: http://unsr.jamesanaya.org/docs/countries/2014 -report-canada-a-hrc-27-52-add-2-en.pdf (accessed 2015 July 16).

Affiliations: Tuberculosis Program Evaluation and Research Unit, University of Alberta (Long), Edmonton, Alta.; University of Ottawa (Ellis), Ottawa, Ont.

Contributors: Richard Long wrote the initial draft of the manuscript. Both authors contributed to the writing and revision of the manuscript, approved the final version to be published and agreed to act as guarantors of the work.

Acknowledgement: The authors thank the staff and students of the Tuberculosis Program Evaluation and Research Unit, University of Alberta, for their help in preparing the manuscript. 